\section{THU0104 BOTH MRI AND HAQ-DI CAN PREDICT RELAPSES FOLLOWING ALL TREATMENT WITHDRAWAL IN MTX-NAÏVE PATIENTS WITH RA IN REMISSION AFTER 12 MONTHS OF ABATACEPT THERAPY IN THE AVERT TRIAL}

H. Ahmad ${ }^{1}$, J. Baker ${ }^{2}$, M. Østergaard ${ }^{3}$, P. Emery ${ }^{4}$, T. Huizinga ${ }^{5}$, J. Ye ${ }^{1}$ S. Banerjee ${ }^{1}$, P. Conaghan ${ }^{4}{ }^{1}$ Bristol-Myers Squibb, Princeton; ${ }^{2}$ Philadelphia VA Medical Center \& the University of Pennsylvania, Philadelphia, United States; ${ }^{3}$ Copenhagen Center for Arthritis Research, Rigshospitalet and University of Copenhagen, Copenhagen, Denmark; ${ }^{4}$ University of Leeds and Leeds Musculoskeletal Biomedical Research Unit, Leeds, United Kingdom; ${ }^{5}$ Leiden University Medical Center, Leiden, Netherlands

Background: Factors predictive of relapse need to be identified to aid therapy withdrawal decisions for patients with RA achieving remission with treatment. AVERT (NCT01142726) was a Phase Illb, randomized, active-controlled trial in patients with early RA. ${ }^{1}$ After a 12-month, double-blind treatment period with abatacept + MTX, or abatacept or MTX monotherapy, patients with DAS28 [CRP] $<3.2$ could enter a 12-month withdrawal period (all treatment stopped).

Objectives: To evaluate post hoc whether MRI scores, patient characteristics and disease activity at Month 12 were predictors of clinical relapse at Month 18 and Month 24 after treatment withdrawal in AVERT.

Methods: Synovitis, erosion and bone oedema in the dominant hand and wrist MRI were scored at Month 12 using the RA MRI scoring system (RAMRIS). Patient characteristics (pain, age, weight, HAQ-DI) and disease measures (CRP, SJC28, TJC28, DAS28 [CRP], CDAI, SDAI) were recorded at Month 12. The influence of these factors on the proportion of patients who relapsed (doubling of TJC28 and SJC28, and DAS28 [CRP] $\geq 1.2$ increase relative to Month 12) by Month 18 and Month 24 was assessed.

Results: A total of 172 patients achieving DAS28 remission (DAS28 [CRP] <2.6) at Month 12 in any treatment group were included in the analysis. Numbers of patients who relapsed at Month 18 and Month 24 were 100 and 113, respectively. Of the patient characteristics, disease activity and imaging factors analysed at Month 12, only MRI synovitis, erosion and oedema scores, as well as HAQ-DI scores, were significantly associated $(p<0.05)$ with relapse status at both Month 18 and Month 24 (Table).

Conclusions: MRI and HAQ-DI scores in patients in DAS28 remission predicted clinical relapses 6 and 12 months after complete drug withdrawal in the AVERT trial. The clinical decision on whether to withdraw therapy in MTX-naïve patients with RA in remission may benefit from an assessment of imaging and physical function prior to drug withdrawal.

References:

[1] Emery P, et al. Ann Rheum Dis 2015;74:19-26.

Disclosure of Interest: H. Ahmad Shareholder of: Bristol-Myers Squibb, Employee of: Bristol-Myers Squibb, J. Baker: None declared, M. Østergaard Grant/research support from: AbbVie, Bristol-Myers Squibb, Janssen, Merck, Speakers bureau: AbbVie, Bristol-Myers Squibb, Boehringer Ingelheim, Celgene, Eli Lilly, Centocor, GSK, Hospira, Janssen, Merck, Mundipharma, Novartis, Novo Nordisk, Orion, Pfizer, Regeneron, Schering-Plough, Roche, Takeda, UCB, Wyeth, P. Emery Grant/research support from: AbbVie, Merck, Pfizer, Roche, Consultant for: AbbVie, Bristol-Myers Squibb, Merck, Pfizer, Roche, Lilly, Novartis, Samsung Bioepis, T. Huizinga Grant/research support from: EU \& Dutch Arthritis Foundation, Consultant for: Abbott Laboratories, Biotest AG, Bristol-Myers Squibb, Crescendo Biosciences, Inc, Novartis Pharmaceuticals Corporation, Pfizer Inc, Roche, sanofi-aventis, Schering-Plough, UCB, Inc., Eli Lilly, Speakers bureau: Abbott Laboratories, Biotest AG, Bristol-Myers Squibb, Novartis Pharmaceuticals Corporation, Pfizer Inc, Roche, sanofi-aventis, Schering-Plough, J. Ye Shareholder of: Bristol-Myers Squibb, Employee of: Bristol-Myers Squibb, S. Banerjee Shareholder of: Bristol-Myers Squibb, Employee of: Bristol-Myers Squibb, P. Conaghan Grant/research support from: Bristol-Myers Squibb, Consultant for: AbbVie, Lilly, Novartis, Pfizer, Speakers bureau: AbbVie, Bristol-Myers Squibb, Roche

DOI: 10.1136/annrheumdis-2017-eular.1649

\section{THU0105 PREDICTION OF RESPONSE TO CERTOLIZUMAB-PEGOL IN RHEUMATOID ARTHRITIS (PRECEPRA) BY FUNCTIONAL MRI OF THE BRAIN - AN INTERIM ANALYSIS OF AN ONGOING INVESTIGATOR INITIATED PHASE III TRIAL}

H. Schenker ${ }^{1}$, A. Hess ${ }^{2}$, L. Konerth ${ }^{2}$, M. Sergeeva ${ }^{2}$, J. Prade $^{2}$, A. Kleyer ${ }^{1}$ M. Reiser ${ }^{1}$, A. Hueber ${ }^{1}$, M. Englbrecht ${ }^{1}$, E. Feist ${ }^{3}$, R.E. Voll ${ }^{4}$, B. Bannert ${ }^{4}$, C. Baerwald ${ }^{5}$, J. Rösch ${ }^{6}$, A. Doerfler ${ }^{6}$, G. Schett ${ }^{1}$, J. Rech ${ }^{1} .{ }^{1}$ Department of Internal Medicine 3, University of Erlangen-Nuremberg; ${ }^{2}$ Institute of Pharmacology and Toxicology, University of Erlangen, Erlangen, ${ }^{3}$ Department of
Rheumatology and Immunology, Charité, Berlin: ${ }^{4}$ Clinic for Rheumatology and Clinical Immunology, University of Freiburg, Freiburg; ${ }^{5}$ Department of Rheumatology, University of Leipzig, Leipzig; ${ }^{6}$ Department of Neuroradiology, University of Erlangen-Nuremberg, Erlangen, Germany

Background: Tumor necrosis factor inhibitors (TNFi) signify a major advance in the treatment of rheumatoid arthritis (RA). However, treatment success initially remains uncertain as one third of patients do not respond adequately to TNFi.

Objectives: We investigated whether brain activity associated to arthritis measured by functional magnetic resonance imaging (fMRI) can function as a predictor of response to TNFiin RA patients.

Methods: This is an interim analysis of the first 50 patients of the PreCePRA trial, a multi-center, double-blind, placebo-controlled fMRI trial on patients with RA. [1] [2] Active RA patients failing csDMARDs with a DAS28-ESR $>3.2$ and at least three tender and/or swollen joints received a baseline brain BOLD fMRI scan upon joint compression at screening. Patients werethen randomized into a 12-week double-blinded treatment phase with placebo (arm 1) or $200 \mathrm{mg}$ certolizumab-pegol eow (arm 2; fMRI Bold signal>2000 voxel i.e. $2 \mathrm{~cm}^{3}$, arm 3; fMRI Bold signal <2000 voxel). LDA 3mo. Primary end point was DAS28-ESR low disease activity at 12 weeks. A 12 weeks follow-up phase in which patients were switched from the placebo to the treatment arm folowed the blinded phase. fMRIwas carried out at baseline as well as after 12 and 24 weeks of or placebo. Results: In 31 patients (responders) baseline signal volume i.e. sum of significantly coupled voxels after the FDR thresholding was significatly higher compared to 19 patients (non-responders) $(p<0.001)$ allowing discrimination between the two groups prior to treatment. In responders we detected an persitent decrease of the BOLD volume from baseline to week 12 and week 24 $\left(r^{2}=0.561\right)$ whereas the BOLD volume in non-responders persitently increased $\left(r^{2}=0.589\right)$.

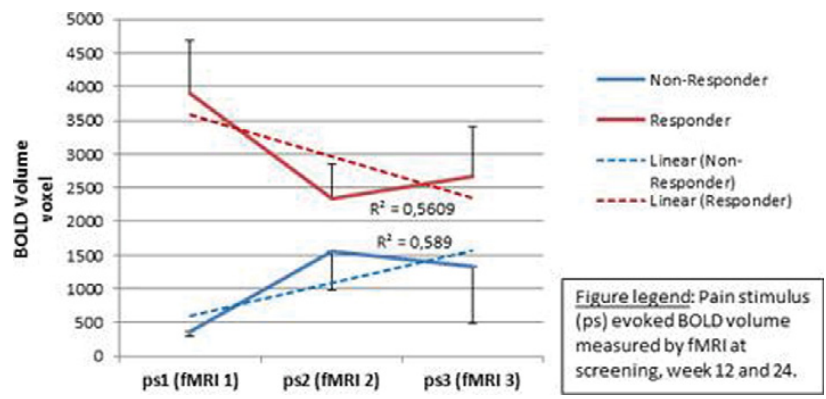

Conclusions: Based on this interim analysis we conclude that high BOLD volumes in fMRI, indicating high-level brain representation of pain in arthritis. These data represent the first encouring signal of the PreCePRA brain fMRI study supporting the concept that increased RA-related brain activity is related to response to $\mathrm{TNFi}$.

References:

[1] Rech, J., et al., Association of brain functional magnetic resonance activity with response to tumor necrosis factor inhibition in rheumatoid arthritis. Arthritis Rheum, 2013.65(2): p. 325-33.

[2] Hess, A., et al., Blockade of TNF-alpha rapidly inhibits pain responses in the central nervous system. Proc Natl Acad Sci U S A, 2011.108(9): p. 3731-6.

Disclosure of Interest: None declared

DOI: 10.1136/annrheumdis-2017-eular.5067

\section{THU0106 ROUTINE CLINICAL ASSESSMENT OF JOINT DAMAGE TO EVALUATE OUTCOME IN RHEUMATOID ARTHRITIS}

H. Bernelot Moens, A. terAvest, D. Berendsen, C. Haagsma. Rheumatology \& Clinical Immunology, Ziekenhuisgroep Twente, Almelo, Netherlands

Background: Early treatment of rheumatoid arthritis (RA) with treat-to-target strategies aims to reduce disease activity and to prevent joint damage. Assessment of the quality of care is commonly based on measurements of disease activity, functioning and well being. In clinical trials, radiographic scores are widely used to assess structural joint damage, but these are not applicable in routine care and limited to hands and feet. Only a few studies evaluated clinical assessment of irreversible joint damage (e.g. surgery) as outcome. The RA articular damage (RAAD) score counts structural damage in all joints that that are affected by RA ${ }^{1}$. It correlates with radiographic damage ${ }^{2}$. We have applied this score since 2014 in routine care.

Abstract THU0104 - Table 1. MRI and HAQ-DI Scores at Month 12 in Patients With vs Without Relapse by Month 18 and Month 24*

\begin{tabular}{|c|c|c|c|c|}
\hline \multirow[b]{2}{*}{ Score } & \multicolumn{2}{|c|}{ Patients with vs without relapse at Month 18} & \multicolumn{2}{|c|}{ Patients with vs without relapse at Month 24} \\
\hline & Estimated difference in scores at Month $12(95 \% \mathrm{Cl})$ & $\mathrm{p}$ value & Estimated difference in scores at Month $12(95 \% \mathrm{Cl})$ & $\mathrm{p}$ value \\
\hline MRI synovitis & $1.051(0.291,1.810)$ & 0.0070 & $1.088(0.256,1.920)$ & 0.0107 \\
\hline MRI erosion & $3.244(1.694,4.795)$ & $<0.0001$ & $3.076(1.550,4.601)$ & 0.0001 \\
\hline MRI oedema & $1.503(0.650,2.356)$ & 0.0007 & $1.423(0.644,2.202)$ & 0.0004 \\
\hline HAQ-DI & $0.194(0.050,0.338)$ & 0.0088 & $0.201(0.050,0.353)$ & 0.0095 \\
\hline
\end{tabular}

${ }^{*}$ Month 18: 92 with relapse, 63 without relapse; Month 24: 103 with relapse, 52 without relapse. 